Article

\title{
The Effects of Demographic Trends on the High-Quality Development of the Chinese Sports Industry
}

\author{
Yuping Duan ${ }^{1}$, Ping Li ${ }^{1, *}$, Di Meng ${ }^{1}$, Te Bu ${ }^{1}$, Xuewei Liu ${ }^{2}$, Stevo Popovic ${ }^{3,4}$ () and Radenko M. Matic ${ }^{4,5}$ \\ 1 College of Physical Education, Hunan Normal University, Changsha 410081, China; \\ yuping0037@163.com (Y.D.); mdgzyx111@163.com (D.M.); bute6891@163.com (T.B.) \\ 2 School of Physical Education and Health, Wenzhou University, Wenzhou 325035, China; \\ liuxuewei199712@163.com \\ 3 Faculty for Sport and Physical Education, University of Montenegro, 81400 Niksic, Montenegro; \\ stevop@ucg.ac.me \\ 4 Western Balkan Sport Innovation Lab, 81000 Podgorica, Montenegro; radenkomatic@uns.ac.rs \\ 5 Faculty of Sport and Physical Education, University of Novi Sad, 21105 Novi Sad, Serbia \\ * Correspondence: lp13808463100@163.com
}

check for updates

Citation: Duan, Y.; Li, P.; Meng, D.; Bu, T.; Liu, X.; Popovic, S.; Matic, R.M. The Effects of Demographic Trends on the High-Quality Development of the Chinese Sports Industry. Sustainability 2022, 14, 1039 https://doi.org/10.3390/su14021039

Academic Editor: Sidonio Serpa

Received: 2 December 2021

Accepted: 7 January 2022

Published: 17 January 2022

Publisher's Note: MDPI stays neutral with regard to jurisdictional claims in published maps and institutional affiliations.

Copyright: (C) 2022 by the authors. Licensee MDPI, Basel, Switzerland. This article is an open access article distributed under the terms and conditions of the Creative Commons Attribution (CC BY) license (https:// creativecommons.org/licenses/by/ $4.0 /)$.

\begin{abstract}
Demographic change is a fundamental characteristic of China's demographic development. The primary problem in China's population development has shifted in recent years from overall pressure to structural challenges. Using data from China's seventh demographic census, this study examines the dynamics of sports consumption growth from the perspective of population structure, analyzes the characteristics of the current population structure and the current state of sports consumption development, and establishes a regression to examine the impact of population structure change trends on sports industry development. The study demonstrates that there are varying degrees of correlation between different demographic trends and the sports industry in China's aging population: the added value per capita of the sports industry is significantly $(p<0.01)$, positively correlated with the proportion of the elderly population and the number of graduates from general higher education institutions. While the expansion of the sports sector continues to be positive, there are numerous issues that need to be addressed. To encourage the development of a high-quality sports industry, proactive countermeasures are proposed to adjust population policy, increase population quality, and promote the comprehensive upgrading of sports consumption.
\end{abstract}

Keywords: demographic structure; sports industry; high-quality development

\section{Introduction}

The Chinese Communist Party's 19th National Congress unambiguously stated the fundamental direction for China's economic structure transformation and upgrade [1]. It is critical to identify new economic growth opportunities in light of the new economic normal and the new social development conditions. Given China's commitment to constructing a strong, modernized socialist country, the economic functions and ideals embedded in the sports industry have elevated it to a new national economic development point that has piqued interest. What is the extent to which economic growth may be promoted? How can its economic effects be fully realized? These are all critical issues that must be addressed.

Sports academia in China is actively engaged in constructive debates regarding the development of the sports sector, and they fall into three basic groups. First, theories examine the current state and trajectory of China's sports industry from a macro perspective and establish an evaluation index system for China's sports industry development. Xia and Hua [2] asserted that accelerating the development of the sports industry is the primary path forward for resolving the major social contradictions in the field of sports in the new era, and made several recommendations, including assuming a dual role of government and market, accelerating supply-side reform, and reforming the policy system. Bao [3] developed a 
dynamic analysis model of sports industry development in time from the structural indexes of sports industry by collating and summarizing the evaluation indexes of sports industry development in the current economic environment of China, in order to provide theoretical guidance for the formulation and implementation of sports industry development policies in China. Second, theories clarify the existing state and challenges facing the regional sports industry's development. Wang and Li [4] combined the theory of regional "growing pole" to examine the necessity and current state of sports industry development in western cities in China. Fu et al. [5] summarized the current state of the sports industry in Beijing and identified the fundamental directions for future development, including continuous expansion of the industry's overall scale, continuous structure optimization, continuous workforce expansion, and steady increase in labor productivity. Thirdly, studies focus on sports tourism, sports culture, and various subsets of the sports sector. Jin et al. [6] stated that in order to expand the sports tourism business, it is necessary to promote resource sharing and co-construction between the sports and tourism industries and to develop a sports brand. He [7] identified the relationship between sports and culture from a philosophical perspective, pointing out that sports contain multiple industrial values and that integrating and developing sports culture and industry is critical for the healthy prosperity of sports culture, as well as proposing corresponding countermeasures for the problems encountered during its development from both a policy and practical perspective.

China's population is a critical factor in its economic and social development; however, there is little research on the development mechanism of the sports industry from a population structure perspective in Chinese sports theories. Few researchers have examined the impact of China's population structure on the development of the sports industries from a single vantage point, such as the urbanization level, the consumption expenditure of urban and rural inhabitants, and the aging of the population. The relationship between population structure and the development of the sports industries is not examined holistically.

Improvements to the demographic structure, such as improved urbanization quality [8], population quality [9], and gender structure optimization [10], are critical drivers of industrial development and structural upgrading, and improvements to industrial structure can further promote demographic structure improvement, such as synergistic industrial structure and urbanization development [11,12].

Another factor to consider throughout the economic restructuring and upgrading process is China's recent demographic imbalance, which is characterized by an aging population [13]. China's economy has enjoyed over forty years of tremendous growth since the reform, and the Chinese economy has garnered worldwide attention. Demographic challenges such as the declining demographic dividend, the population's accelerated aging, the population's slowing growth, the gender imbalance, and the population's uneven spatial distribution are increasingly emerging.

Because demographic changes have a significant impact on the industry's production and demand conditions, it is critical to clarify the relationship between demographic changes and the development of the sports industry, as well as its degree of influence. On the basis of the foregoing, this paper examined the interaction between demographic change and the sports industry, with the goal of promoting high-quality sports industry development as a starting point.

\section{Methods}

\subsection{Trend Analysis of Demographic Changes in China}

The demographic structure primarily influences the development and structural upgrading of the sports industry through production factors and demand conditions, which are expressed demographically in terms of total population, male-to-female sex ratio, population age structure, urbanization rate, and education level. The total population is the sum of a country's or a region's population across time. The population sex ratio is defined as the ratio of males to females. The term "population age structure" refers to the proportion of each age group in a country's or a region's total population at a given moment. 
Furthermore, the distribution of the population is determined by long-term geographical and historical factors and is influenced by elements such as productivity, scientific and technology development status, economic and social development, and political issues. Based on this, a trend analysis of the demographic changes in China was conducted from the seventh national demographic census in 2020 [14].

\subsection{Regression Analysis of the Effects of Demographic Changes on the Sports Industry's Development}

After conducting a realistic analysis and taking into account all available data, the value added per capita of China's sports industry from 2006 to 2019 was chosen to reflect the industry's development, and secondary indicators such as total population, sex ratio, elderly population proportion, urbanization rate, and number of graduates from general higher education institutions were chosen to assess demographic changes. Data on the added value of the sports industry were obtained from the General Administration of Sports of China [15].

From 2006 to 2019, the added value of the sports industry (Y) was used as the dependent variable to represent the industry's development stage, while the total population $(X 1)$, the sex ratio $(X 2)$, the urbanization rate (X3), the proportion of elderly people aged 60 and over (X4), and university education (X5) were used as independent variables. Multiple linear regression analysis was performed to determine the association between variables. The data were first logarithmically transformed without altering the trend of the original data. Differences were considered statistically significant at a $p$-value of $p<0.05$.

\section{Results}

\subsection{Inertia in Total Population Growth and Slowdown in Population Growth}

According to public data from the seventh national demographic census in 2020 (Table 1), China's total population reached 1.41 billion people, maintaining the trend of continued growth. Compared to the sixth census data [16], it increased by 72.05 million people, a 5.38\% increase. The population's natural growth rate recovered, and the trend of slowing total population growth continued, with an average annual growth rate of $0.53 \%$, which is $0.04 \%$ lower than the sixth census. This is a result of the interaction of economic and social development, changes in traditional fertility culture, and population policy. Clearly, China's period of fast population expansion has come to an end, and at this point, the impact of this trend on the economy and society's sustainable development is dialectical. On the one hand, the fundamental situation of China's large population base has not changed, and population and resources remain tightly balanced. On the other hand, the trend toward slower population growth requires proactive measures and long-term planning to promote long-term balanced population development.

Table 1. Comparing the sixth and seventh national censuses of the population.

\begin{tabular}{ccc}
\hline & $\begin{array}{c}\text { Sixth National } \\
\text { Demographic Census }\end{array}$ & $\begin{array}{c}\text { Seventh National } \\
\text { Demographic Census }\end{array}$ \\
\hline Total population (per & 134,091 & 141,178 \\
10,000 inhabitants) & 105.21 & 105.07 \\
Population sex ratio (female = 100) & 8.90 & 13.50 \\
Elderly people aged 60 and above (\%) & 49.95 & 63.89 \\
Urbanization rate (\%) & 8930 & 15,467 \\
University education (per & & \\
100,000 inhabitants) &
\end{tabular}

Data obtained from the National Bureau of Statistics of China.

\subsection{The Population's Sex Ratio Is Generally Acceptable, and the Gender Structure Has Gradually Improved}

According to the seventh national demographic census, the sex ratio of China's total population in 2020 is 105.07 (Table 1), which is slightly lower than the sex ratio in the sixth 
census. In terms of births, the sex ratio has decreased significantly over the last decade, and the sex ratio of China's population is gradually normalizing and the gender structure is improving. Improving the gender structure may have a wide range of socioeconomic consequences, and the gender dividend generated by increasing gender equality in China will provide significant extra-economic gains, which will serve as a major engine of growth in the next years. Thus, balancing the population sex ratio is a crucial measure for China's economic and social development to be healthy.

\subsection{The Elderly Population Is Increasing in Size, and the Pace of Population Aging Is Accelerating}

At the moment, China's population age structure is as follows: first, the proportion of children in the population is declining; second, the working-age population is progressively declining; third, the population is aging, and the aging process is clearly accelerating. According to the seventh national demographic census [14], mainland China's total elderly population is 264 million, accounting for $18.7 \%$ of the overall population (Table 1). The demographic structure has entered a period of profound aging, with the working-age population declining and the senior population expanding, thereby raising the social burden and increasing demand for fundamental public services. The social security system, the medical and health care system, as well as the job and retirement systems, are all facing significant challenges. The realistic urgency of actively managing with an aging population has never been greater. The 19th Communist Party of China Central Committee's Fifth Plenary Session elevated actively coping with the aging population to a national strategy [17], and establishing a national social and livelihood system capable of adapting to the normalization of an aging society has become an urgent requirement for sustainable and healthy economic and social development.

\subsection{Accelerated Urbanization and Increased Population Mobility}

China's urban population has continued to grow in recent years, with the urbanization rate expected to reach $63.9 \%$ in 2020 (Table 1), indicating a rapid growth trend and a pattern of significant migration and mobility between urban and rural areas. The population that is migrating to cities is not only productive but also consumer, with high consumption and investment driving rapid growth. This is a critical source of power for achieving high-quality economic development, but it also creates new requirements for improving urbanization quality and promoting coordinated regional development. According to the All-China Women's Federation's Research Report on the Situation of Left-behind Children in Rural Areas and Urban-Rural Mobility in China [18], there are 61,025,500 rural leftbehind children and 35,810,000 mobile children in China, and these children generally have low living standards, low educational level, and mental health problems, as a result of a violent collision between the current social livelihood system and the rapid rate of population urbanization. The path to high-quality urbanization has emerged as a defining feature of China's social development.

Similarly, a reasonable and acceptable population distribution is a necessary requirement for modern sports development [19]. The continued development of central regional cities, which have high concentrations of high-quality medical care, education, infrastructure, information resources, and capital, attracts additional high-quality resources from surrounding towns, i.e., the "siphon effect" of cities [20], exacerbating the imbalance of sports development, which includes large-scale stadium facilities, large-scale sporting events, and high-level sporting talent. However, the large population concentration in key regional centers will create significant obstacles for the growth of sports, which will be detrimental to the long-term, high-quality development of sports.

\subsection{Significant Improvements in the Quality of the Population and an Increase in Human Capital}

The population's quality is the precondition and basis for human beings to know and transform the world, and it can be measured in terms of a group's education level, school attendance rate, and numerous physical quality indicators. In 2020, mainland China had 
a university education rate of 15,467 per 100,000 inhabitants (Table 1 ), and the number of graduates from higher education and high school is increasing. Human capital has expanded dramatically, as has the proportion of skilled labor in the entire population, unleashing the "talent dividend". It is critical to leverage the talent dividend to mitigate the negative effects of China's dwindling demographic dividend on the economy, further promoting industrial transformation and upgrading, as well as promoting sustainable, coordinated, and healthy economic and social development. Creating new impetus and vitality is also critical to ensuring that China's sports industry continues to develop at a high level and becomes a new economic growth center.

\subsection{Analysis of Correlations between Various Demographic Trends and the Sports Industry}

The normality test for the value added of the sports industry in China from 2006 to 2019 revealed a significant level of $0.063(p>0.05)$, indicating that the dependent variable value added per capita of the sports industry is a normal variable that can be analyzed for regression. As illustrated in Table 2, the degree of correlation between various demographic changes and the sports industry varies. The value added per capita of the sports industry is significantly and positively correlated with the total population, urbanization rate, elderly population proportion, and number of graduates from general higher education institutions, with correlation coefficients of the proportion of elderly members of the population (0.986), urbanization rate (0.936), and number of graduates from general higher education institutions (0.878), in that order of magnitude. The sex ratio is inversely proportional to the value added per capita of the sports industry.

Table 2. Analysis of correlations between various demographic trends and the sports industry.

\begin{tabular}{|c|c|c|c|c|c|}
\hline Indicators & $\begin{array}{l}\text { Value } \\
\text { Added per } \\
\text { Capita of } \\
\text { the Sports } \\
\text { Industry }\end{array}$ & Sex Ratio & $\begin{array}{c}\text { Urbanization } \\
\text { Rate }\end{array}$ & $\begin{array}{c}\text { Elderly } \\
\text { People } \\
\text { Aged } 60 \\
\text { and Above }\end{array}$ & $\begin{array}{l}\text { University } \\
\text { Educa- } \\
\text { tion }\end{array}$ \\
\hline $\begin{array}{l}\text { Value added per capita } \\
\text { of the sports industry }\end{array}$ & 1 & & & & \\
\hline Sex ratio & $-0.821 *$ & 1 & & & \\
\hline Urbanization level & $0.936^{*}$ & $-0.861 *$ & 1 & & \\
\hline $\begin{array}{c}\text { Elderly people aged } 60 \\
\text { and above }\end{array}$ & $0.986 *$ & $-0.842 *$ & $0.977 *$ & 1 & \\
\hline University education & $0.878 *$ & $-0.868 *$ & $0.982 *$ & $0.933 *$ & 1 \\
\hline
\end{tabular}

\subsection{Modeling by Multiple Regression}

The regression results are shown in Table 3 . The adjusted $\mathrm{R}^{2}$ value is 0.996 , indicating that $99.6 \%$ of the independent variables can account for the dependent variable and that the model fits well. However, the P-values for X1, X2, X3, X4, and X5 are all more than 0.05 , indicating that none of the variables pass the significance test. Additionally, the Durbin-Watson value and the VIF value are too high, indicating that the autocorrelation between the model's variables is strong and cointegration exists, necessitating further model modification.

The main idea behind stepwise regression analysis is to gradually add or subtract a variable from all available independent variables until the ideal regression model is produced. As illustrated in Table 4, the variables were screened using a stepwise regression model, and the variables X1 and X2 were eliminated to obtain the optimal model. Each variable had a $p$-value less than 0.05 , the VIF and Durbin-Watson values were ideal, and there was no multicollinearity between the variables and the arithmetic. The model is regarded as being well-fitted. 
Table 3. The results of a multiple regression analysis.

\begin{tabular}{cccccc}
\hline Model & $\begin{array}{c}\text { Non- } \\
\text { Standardized } \\
\text { Regression } \\
\text { Coefficients } \\
\text { (Beta) }\end{array}$ & $\begin{array}{c}\text { Standardized } \\
\text { Regression } \\
\text { Coefficients } \\
\text { (Beta) }\end{array}$ & $t$-Value & $p$-Value & VIF \\
\hline Correlation & 7.488 & $\backslash$ & 0.284 & 0.783 & $\backslash$ \\
X1 & -3.823 & -0.030 & -0.688 & 0.509 & 4.221 \\
X2 & 2.147 & 0.290 & 1.080 & 0.308 & 164.094 \\
X3 & 2.862 & 0.564 & 3.301 & 0.009 & 66.443 \\
X4 & 0.475 & 0.129 & 0.999 & 0.344 & 37.927 \\
\hline
\end{tabular}

$\bar{X}$, sex ratio; $X 2$, urbanization rate; $X 3$, proportion of elderly people aged 60 and above; $X 4$, university education.

Table 4. The results of the stepwise regression model.

\begin{tabular}{|c|c|c|c|c|c|c|}
\hline & Model & $\begin{array}{c}\text { Non- } \\
\text { Standardized } \\
\text { Regression } \\
\text { Coefficients } \\
\text { (Beta) }\end{array}$ & $\begin{array}{l}\text { Standardized } \\
\text { Regression } \\
\text { Coefficients } \\
\text { (Beta) }\end{array}$ & $t$-Value & $p$-Value & VIF \\
\hline \multirow{3}{*}{1} & Correlation & -21.707 & $\backslash$ & -23.417 & 0.000 & $\backslash$ \\
\hline & $\mathrm{X} 3$ & 7.455 & 0.994 & 31.882 & 0.000 & 1.000 \\
\hline & Correlation & -13.952 & 1 & -6.779 & 0.000 & 1 \\
\hline \multirow[t]{3}{*}{2} & X3 & 4.222 & 0.563 & 5.069 & 0.000 & 28.146 \\
\hline & $\mathrm{X} 4$ & 2.228 & 0.439 & 3.952 & 0.02 & 28.146 \\
\hline & \multicolumn{6}{|c|}{$\mathrm{R}^{2}=0.994 ;$ Durbin-Watson $=2.052$} \\
\hline
\end{tabular}

$\mathrm{X} 3$, proportion of elderly people aged 60 and above; $\mathrm{X} 4$, university education.

As indicated in Table 4, model 2 is the ideal model, and the proportion of elderly people aged 60 and above has the biggest impact on the value added per capita of the sports industry, followed by the university education. Thus, the proportion of elderly people aged 60 and above and the university education have a more direct effect on the expansion of the sports industry as it develops. The optimum linear regression equation with the value added per capita of the sports industry $(\mathrm{Y})$ as the dependent variable and the proportion of elderly people aged 60 and above (X3) and university education (X4) as the independent variables is $\mathrm{Y}=-13.952+4.222 \mathrm{X} 3+2.228 \mathrm{X} 4$. As can be observed, for every $\log$ increase in the proportion of elderly people aged 60 and above, the value added per capita of the sports industry grows by 4.222 logarithms. The university education has a positive relationship with the value added of the sports industry, i.e., for each log increase in the university education, the value added per capita of the sports industry grows by 2.228 logarithms.

\section{Discussion}

The sports industry is a collection of organizations and sectors that manufacture sports products to meet the needs of people who watch sports events and performance activities and who participate in sports and fitness activities [21], and it plays an irreplaceable role in meeting people's growing needs for a better life. The Central Committee of the Chinese Communist Party and the State Council place a premium on the development of the sports industry, promulgating policy documents such as "Opinions on Accelerating the Development of Sports Industry and Promoting Sports Consumption" [22], "Outline for Building a Leading Sports Nation" [23], and "Opinions on Promoting Mass Sports, Sports Consumption and High Quality Development of Sports Industry" [24], all of which promote high-quality development of the sports industry. The sports industry has grown quickly as a result of these initiatives and has become a significant driver for economic and social growth. From the perspective of the sports industry's growth rate, the ratio 
of the sports industry to the gross domestic product has been increasing, and its growth rate is significantly higher than the gross domestic product's growth rate [25], indicating enormous market potential. From an industrial perspective, the entire scale continues to rise, the macro trend of the sports sector's development remains stable, and its economic contribution continues to grow. Internally, the sports service sector's share of overall industry value continues to grow, and the sports industry's structure continues to improve, contributing to economic transformation and upgrading.

The proportion of the elderly population aged 60 and above is positively correlated with the high-quality development of the sports industry, implying that the growth of the total elderly population benefits the development of the sports industry. China's aging population is rapidly increasing in size and complexity, and the task of aging is critical to the country's economic and social stability. The 14th Five-Year Plan and the outline of the 2035 Vision [26] both emphasized the importance of implementing a national strategy to actively address the aging population. The sports industry has benefited from favorable policies and development opportunities as an effective means of coping with the challenges of aging. According to the national strategic vision for population aging [26], the aging society's development logic is to promote industrial development through continuous stimulation of industrial innovation. Seniors have a strong desire for sports, as well as thrifty habits and consumption power. Stimulating the elderly population's consumption power through the provision of appropriate sports products and services, as well as targeted efforts, reform, and innovation to drive the elderly population's sports consumption market [27], contributes to the creation of new sports consumption growth points, transforming the aging population into a powerful driving force for the high-quality development of the sports industry, or the "sports silver hair economy".

The number of graduates from general higher education institutions is positively correlated with the development of the sports industry, implying that raising the overall educational level can contribute to the industry's high-quality development. Economic development has shifted away from factors such as population size and toward factors such as population quality in the knowledge-based economy, as evidenced by the sports industry. To begin, education can influence people's knowledge and investment in health [28], thereby increasing sports consumption; at the same time, the higher the education level, the greater the level of consumption demand [28], which stimulates the optimization of the sports industry structure. Furthermore, education improvement fosters the development of talents and innovation necessary for the high-quality development of the sports industry, overcoming the long-standing disadvantage of being at the bottom of the global sports industry chain, and guiding the traditional sports industry toward upgrading and replacement.

\section{Implications}

While the sports industry's development continues to improve, it should be noted that China's sports industry is still in its infancy, and issues such as the industry's small scale, insufficient release of consumption potential, insufficient effective supply of products and services, and insufficient innovation capacity must be addressed. This study makes the following recommendations for promoting the high-quality development of the sports industry from a population structure perspective.

\subsection{Encourage Sustainable Expansion of the Overall Population as Well as the Size and Scope of the Sports Industry}

Population is a critical component of economic and social development, and sports population is critical to achieving sustainable development of the sports industry, which is influenced by a variety of factors including policy and regulation, economic development level, education level, and overlapping life concepts. The sports population is defined in this study in a broad sense, as the aggregate of all persons who engage in sports activities, pay attention to sports forms and policies, and consume sports-related services. 
Promoting a sustainable increase in the whole sports population will require the collaboration of all levels of society. First, the community's construction should be enhanced. With China's rapid urbanization, the community has developed into the primary activity space for the sports population, and it is necessary to expand sports facilities and venues in the community and to strengthen social sports instructor training based on the actual needs of people participating in sports and fitness activities, so that people can have a better sports experience and thus promote the growth of the sports population. Second, it is critical to actively promote the formation of sports organizations, work to increase the popularity of physical fitness activities, and expeditiously organize social sports through sports organizations, all of which contribute to a better understanding of the sports population's development in the leisure era. Finally, it is critical to develop school sports infrastructure and to cultivate students' lifelong sports consciousness. The student stage is a critical time for developing individual sports concepts, and focusing on the development of school sports and cultivating students' physical activity habits contributes to the sports population's stability [29].

On the other hand, a moderate population size is necessary for the healthy growth of sports, and an excessive total population in society can result in a severe lack of allocation of sports resources. At the societal level, a big population increases demand for public land, and a reduction in area dedicated to sports facilities is detrimental to the healthy development of sports. At the elementary school level, an excessive number of students means fewer resources per pupil for school sports, which will fall short of meeting the health standards for the sports environment.

\subsection{Optimize the Sex Ratio of the Population and Provide New Momentum for the Sports Industry's Development}

The economic benefits of the gender dividend are primarily manifested in full labor participation, the elimination of occupational segregation, and resistance to economic recession [30]. This can also be understood as the optimization of the population sex ratio, the purpose of which is to ensure equal employment opportunities for women in order to increase women's labor participation rates and, by extension, economic growth. As a result, we must constantly reflect on and reject the existence or occurrence of gender inequality in the sports industry, as well as explore numerous avenues for unleashing the gender dividend in order to encourage the sports industry's further development. The gender dividend's economic impact does not need total equality between men and women in sports, but rather gender equality, which includes equal opportunities, resources, and rights.

Increases in women's social standing will liberate more women from home and parenting responsibilities, resulting in a benefit to macroeconomic growth via increases in female labor force participation and social participation rates. While increasing female labor force participation will have an effect on fertility rates and exacerbate the social burden associated with population aging, a low fertility rate will promote per capita investment in education and human capital accumulation, accelerating the economic transition from "quantitative" to "qualitative" development. As a result, families and society should provide a safe and comfortable atmosphere for women, recognize and support their involvement in sports and fitness activities, and eliminate stereotypes.

\subsection{Changing the Population's Age Composition to Foster New Growth in Sports Consumption}

According to the 2014 survey on the state of national fitness activities, only $13.7 \%$ and $12.4 \%$, respectively, of the total population aged 20-29 and 30-39 years old participate in fitness activities on a regular basis [31]. The primary reason for this issue is China's social and familial structure, which places a significant burden on young and middle-aged people as the backbone of social progress, resulting in a dearth of spare time. It is critical for society to provide them with a healthy work environment and as many opportunities for physical activity as possible. This is an effective method for increasing workers' physical 
fitness, work efficiency, and quality of life, as well as a means of breaking the sports population bottleneck in this age group and promoting sports consumption growth, which is a necessary step toward healthy economic and social development. The rapid aging of China's population has resulted in a surge in demand for sports. Due to the fact that older adults have a stable economic base and plenty of free time, sports for the elderly demand attention. Regular engagement in sporting activities by the senior population benefits not only their own health but also alleviates the strain on family and society.

The venue and equipment are critical components of ensuring sports consumption. There are significant disparities in the fitness routines preferred by different age groups of the sports population. Unlike the elderly, young and middle-aged people prefer swimming, dancing, and a variety of ball games that require a large venue and a high level of specialization. The lack of an effective supply of venue facilities results in an egregious structural mismatch between the public's diverse fitness needs and the supply. To stimulate new growth in sports consumption, it is necessary to rationalize the sports industry's structure and more effectively meet the public's consumption needs. This can be accomplished by deepening supply-side structural reform in the field of sports and promoting coordinated development within the sports industry on the basis of effective identification of consumer needs.

\subsection{Enhancing the Population's Quality of Life and Fostering the Development of a High-Quality Sports Industry}

The core tenet of endogenous growth theory is that the economy's endogenous technical progress is necessary for sustained economic growth. The rapid process of marketization, the shift in economic development stage, and the shift in labor supply and demand in China have all resulted in dramatic alterations to the traditional economic growth drivers. The trend toward "quantitative" demographic dividends is irreversible, and "human capital dividends" will supplant "demographic dividends" as the main mechanism for boosting economic growth [32]. As a result, developing a strong human capital country will be an unavoidable strategic decision for China's future economic development strategy. The overall number of employees in the sports system was 148,181 in 2019 [33], highlighting the structural mismatch between supply and demand in the sports labor market. Thus, efforts should be made to cultivate top-tier talent in the field of sports in order to build human capital, strengthen scientific and technological innovation capabilities, boost overall economic efficiency, and provide an endogenous impetus for the high-quality development of the sports industry.

Science and technology have been elevated to a significant position in the country's present economic transition. It is an unavoidable option to employ current science and technology to develop the sports industry in order to meet the leisure and entertainment needs of sports consumers in the new era, as well as to increase the high-tech content of the sports industry's development. Due to the country's strong support for the sports industry, public awareness of sports is growing, and more capital and talent are flowing into the sports industry. The traditional sports industry must abandon its former business model, which was entirely devoted to the sporting environment. The modern sports industry should leverage internet tools such as big data, the Internet of Things, and edge computing to achieve a breakthrough and leap, allowing sports to be integrated into people's daily lives and thus promote the high-quality development of the sports industry, thereby forming a virtuous cycle of human resources, capital, and development.

\subsection{Increase Public Knowledge of Health Issues and Advocate for a Thorough Upgrade of Sports Consumption}

According to Maslow's Hierarchy of Requirements, if basic needs are met, people will eventually pursue more comprehensive growth. The development of China's economy and the ongoing improvement of people's living standards have resulted in a significant increase in people's health consciousness. People used to be more concerned with clothing, food, housing, and transportation in the past. People have begun to place a higher premium 
on health [25]. The desire for personalized sports and fitness, enhanced sports training, square dancing, and other mass sports activities has transformed urban and rural areas into a beautiful landscape in China. As a result of the epidemic since 2020, individuals are paying more attention to their health, and exercise awareness and habits have been significantly improved. According to the Research Report on Mass Fitness Behavior and Consumption in 2021, the average annual total consumption of mass fitness in 2021 will be $35 \%$ greater than in 2020, and the willingness to meet sports-related consumption demands will continue to grow [33]. However, the general public's health consciousness and the sports industry continue to lag behind China's economic progress. It is vital to further raise the general public's awareness of health issues, emphasizing the need for physical activity and disease prevention in particular. Governments at all levels should create and coordinate activities to promote the growth of China's sports industry, with the goal of establishing a healthy China and a powerful sports nation.

\section{Conclusions}

In conclusion, China's economy has shifted from "rapid" to "quality" growth, and traditional economic dynamics have shifted dramatically, with the demographic structure becoming a significant factor affecting economic growth. As a new starting point, we must actively address the negative impact of demographic changes while seizing potential development opportunities, transforming demographic changes into a driving force for high-quality sports industry development, and achieving long-term sustainable sports industry development.

Author Contributions: Conceptualization, P.L. and T.B.; methodology, P.L. and T.B.; formal analysis, Y.D., X.L., and D.M.; writing-original draft preparation, P.L. and X.L.; writing-review and editing, Y.D., T.B., S.P., R.M.M., and D.M.; project administration, P.L. and T.B.; funding acquisition, P.L. and T.B. All authors have read and agreed to the published version of the manuscript.

Funding: This research was made possible by financing from the Ministry of Education's 2019 Philosophy and Social Science Foundation Project, "Interest Game and Institutional Innovation: A Historical Review and Reflection on China's Football Reform" (19YJA890001).

Institutional Review Board Statement: Not applicable.

Informed Consent Statement: Not applicable.

Data Availability Statement: Data are available upon reasonable request from the corresponding authors.

Conflicts of Interest: The authors declare no conflict of interest.

\section{References}

1. China Daily. Full Text of Xi Jinping's Report at 19th CPC National Congress. Available online: https://www.chinadaily.com.cn/ china/19thcpcnationalcongress/2017--11/04/content_34115212.htm (accessed on 14 November 2017).

2. Xia, J.; Hua, K. The rationale and path for accelerating the growth of the sports business in the context of the new era's transformation of the major social contradictions. Sports Culture Guide 2018, 2, 1-6.

3. Bao, H. Research on the evaluation index system and dynamic analysis of the Chinese sports industry's development. J. Guangzhou Sport University 2019, 3, 16-22.

4. Wang, J.; Li, N. Strategic thinking on the development of the sports sector in western cities of China based on the regional "growing pole" theory. J. Guangzhou Sport University 2016, 4, 12-15.

5. Fu, Q.; Liu, Y.; Xiao, S.; Wang, P. Research on the current state and characteristics of China's sports industry development-Using Beijing's sports industry development as a case study. J. Nanjing Sports Inst. 2015, 3, 73-80.

6. Jin, Y.; Yang, Y.; Zhu, Y. Research on the integration of the sports and tourist industries in China. Sports Culture Guide 2019, 6, 82-87.

7. He, W. Exploration of the growth route and strategy of sports culture in the setting of multi-dimensional integration. J. Beijing Sport University 2020, 12, 35-45.

8. Duo, S. The mechanism and empirical analysis of urbanization's impact on industrial transformation and upgrading-a study of 283 prefecture-level cities in China. Enterp. Economy 2013, 6, 131-134. 
9. Zhang, Y.; Dong, Q.; Fang, J.; Zong, W. China's service industry growth in the era of population quality dividend. Economist 2020, $3,56-65$.

10. Lu, J.; Wei, X. The gender dividend in China: Its various manifestations, windows of opportunity, and future prospects. Shandong Soc. Sci. 2021, 3, 60-69.

11. Jacobs, J. The Economy of Cities; Random House New York: New York, NY, USA, 1969.

12. Porter, M.E. The competitive advantage of nations. Competitive Intelligence Rev. 1990, 1, 14. [CrossRef]

13. Wolrd Health Organization. Ageing and Health in China. Available online: https://www.who.int/china/health-topics/ageing (accessed on 30 December 2021).

14. National Bureau of Statistics of China. Main Data of the Seventh National Population Census. Available online: http://www. stats.gov.cn/english/PressRelease/202105/t20210510_1817185.html (accessed on 11 May 2021).

15. General Administration of Sports of China. Sports Statistics. Available online: https://www.sport.gov.cn/n315/n329/index.html (accessed on 10 May 2021).

16. National Bureau of Statistics of China. Communiqué of the National Bureau of Statistics of People's Republic of China on Major Figures of the 2010 Population Census [1] (No. 1). Available online: http://www.stats.gov.cn/english/NewsEvents/201104/t201 10428_26449.html (accessed on 28 April 2011).

17. The National People's Congress of the People's Republic of China. Full Text: Communique of 6th Plenary Session of 19th CPC Central Committee. Available online: http:/ / www.npc.gov.cn/englishnpc/c23934/202111/c91cf9aa6aee453b8ce8160b00cc8ba8 .shtml (accessed on 12 November 2021).

18. Project Group of the All-China Women's Federation. Research Paper on the Situation of Rural Left-Behind Children and Urban-Rural Migratory Children in China. Available online: http:/ /www.women.org.cn/ (accessed on 10 May 2013).

19. Dai, J. Sports Sociology; Nanjing University Press: Nanjing, China, 2015.

20. Xu, Z.; Sun, T. The Siphon effects of transportation infrastructure on internal migration: Eevidence from China's HSR network. Appl. Econ. Lett. 2021, 28, 1066-1070. [CrossRef]

21. Lin, X. The existing state of the Chinese sports sector and its anticipated development trajectory. In Proceedings of the Academic Conference on China's Sports Industry; 2020; pp. 46-47.

22. The State Council of The Peopole's Republic of China. Opinions on Accelerating the Development of Sports Industry and Promoting Sports Consumption, Guofa [2014] No. 46. Available online: http://www.gov.cn/zhengce/content/2014--10/20/ content_9152.htm (accessed on 20 October 2014).

23. The State Council of The Peopole's Republic of China. Outline for Building a Leading Sports Nation. Available online: http://english.www.gov.cn/policies/latestreleases/201909/02/content_WS5d6d1a96c6d0c6695ff7faa3.html (accessed on 2 September 2019).

24. The State Council of The Peopole's Republic of China. Opinions on Promoting Mass Sports, Sports Consumption and High Quality Development of Sports Industry. Available online: http://www.gov.cn/zhengce/content/2019--09/17/content_5430555.htm (accessed on 17 September 2019).

25. National Bureau of Statistics of China. Announcement of 2016 National Sports Industry Total Size and Value Added Data. Available online: http:/ /www.stats.gov.cn/tjsj/zxfb/201801/t20180113_1573014.html (accessed on 13 January 2018).

26. UNDP in China. Issue Brief-China's 14th five-year plan. Available online: https://www.cn.undp.org/content/china/en/ home/library/environment_energy/issue-brief---china-s-14th-five-year-plan.html (accessed on 23 July 2021).

27. Ren, B. Theoretical Analysis and Econometric Evidence of China's Aging Population Boosting Sports Industry Development. Shandong Sports Sci. Technol. 2020, 4, 1-6.

28. Beraldo, S.; Montolio, D.; Turati, G. Healthy, educated and wealthy: A primer on the impact of public and private welfare expenditures on economic growth. J. Socio-Econ. 2009, 38, 946-956. [CrossRef]

29. Lin, F. Sports Geography; Zhejiang University Press: Zhejiang, China, 2017.

30. Zhu, H.; Lu, J. From Demographic Dividend to Gender Dividend: Theoretical Reflections on the Broad Socioeconomic Effects from a Gender Equality Perspective. Nankai J. (Philos. Lit. Soc. Sci.) 2021, 2, 41-50.

31. General Administration of Sports of China. Bulletin of the 2014 National Fitness Activities Survey. Available online: http: / / www.sport.gov.cn/n316/n340/c212777/ content.html (accessed on 30 November 2015).

32. Zhang, T. From quantitative "demographic dividends" to qualitative "human capital dividends"—Another discussion of China's economic growth's power transition mechanism. Econ. Sci. 2016, 5, 5-17.

33. China Sporting Goods Federation. Research Report on Public Fitness Behavior and Consumption in 2021. Available online: http:/ / csol.sports.cn/ (accessed on 18 May 2021). 